\title{
Formação Online de Professores em Robótica Educacional com Práticas no
}

\section{Simulador Tinkercad}

\author{
Kenia Luiza Oliveira*, Maria Aparecida de Faria da Silva ${ }^{\star \star}$, Márcia Oliveira $^{\star \star \star}$, \\ Rayane Scarpati ${ }^{\star \star * *} ;$ Vanessa Battestin ${ }^{\star \star \star \star *}$
}

\section{Resumo}

Nas últimas décadas, as transformações tecnológicas provocaram mudanças nas relações sociais, políticas, econômicas e consequentemente no papel da escola contemporânea. Esse cenário acelerou o desafio por parte dos professores e demais profissionais da educação na busca de maior qualificação, exigindo competências e habilidades que se tornaram fundamentais na sociedade atual. Nesse sentido, este trabalho apresenta o uso do simulador Tinkercad em um curso virtual de introdução à robótica promovido por alunos do programa de Mestrado Profissional, Educação em Ciências e Matemática - EDUCIMAT - IFES/CEFOR, como uma extensão da disciplina de "Tecnologias Educacionais IV". O Tinkercad é uma plataforma online que permite a simulação de circuitos eletrônicos digitais, incluindo o uso do Arduino. A importância deste trabalho se evidencia no fato de que a modalidade de ensino e de aprendizagem em ambiente virtual se tornou uma realidade nas últimas décadas, em especial no contexto da pandemia do Covid-19.

Palavras-chave: Robótica Educacional, Formação de professores, Arduino, Tinkercad.

* Mestranda no Programa de Pós-graduação em Educação em Ciências e Matemática do Instituto Federal de Educação, Ciências e Tecnologia do Espírito Santo. Professora da Rede Pública Municipal de Vila Velha ES, Brasil. E-mail: keniarobotica@gmail.com

* Mestranda no Programa de Pós-graduação em Educação em Ciências e Matemática do Instituto Federal de Educação, Ciências e Tecnologia do Espírito Santo. Professora da Rede Pública Municipal de Vila Velha ES, Brasil. E-mail: cidadfaria72@gmail.com

*** Mestranda no Programa de Pós-graduação em Educação em Ciências e Matemática do Instituto Federal de Educação, Ciências e Tecnologia do Espírito Santo. Licenciada em Química. E-mail: rayanescarpati@gmail.com

**** Doutorado em Engenharia Elétrica pela Universidade Federal do Espírito Santo, Brasil. Professora do Instituto Federal do Espírito Santo, Brasil. E-mail: clickmarcia@gmail.com

***** Doutorado em Educação pela Universidade Federal do Espírito Santo, Brasil. Professora Titular do Instituto Federal de Educação, Ciência e Tecnologia do Espírito Santo, Brasil. E-mail: vanessa.battestin@gmail.com 


\section{Introdução}

O processo de ensino e de aprendizagem tem sofrido influência direta das mudanças tecnológicas que estão ocorrendo no mundo, gerando novas perspectivas em relação à educação. Em meio a tantas mudanças, ainda é possível verificar que há um distanciamento entre a realidade proposta para a promoção da aprendizagem com o uso das tecnologias e o que é vivenciado nas escolas brasileiras, pois ainda há escolas sem computadores, sem acesso à internet e professores sem formação adequada para o uso das tecnologias educacionais.

Dentre as tecnologias educacionais, a Robótica, num contexto pedagógico, vem ganhando notável destaque, apresentando muitas vantagens no processo de aprendizagem, uma vez que, segundo Zilli (2004), favorece a interdisciplinaridade, promovendo a integração de diversos conceitos e preparando o aluno para o trabalho colaborativo. Dessa forma, no lugar do quadro, giz e cadeiras enfileiradas, os kits de robótica, compostos por dispositivos eletrônicos, possibilitam maior desenvolvimento da criatividade a partir do learning by doing, isto é, pelo aprender fazendo.

Diante desse contexto, a robótica educacional, alinha-se às novas tendências para a aprendizagem ativa, pois o aluno se torna protagonista no processo de aprendizagem tanto na fase de criação de um robô, quanto na resolução de problemas encontrados durante o processo de criação. Esse conjunto de ações leva o aluno a buscar respostas nos conhecimentos já existentes e colabora para a construção de novos conhecimentos. A prática da robótica também provoca mudanças na maneira de pensar as ações pedagógicas, a organização curricular e a formação de professores para atender os interesses educacionais.

De acordo com Manfredini (2014), as tecnologias digitais são importantes recursos para a educação e é necessário desenvolver trabalhos no sentido de capacitar os professores para o uso correto dessas tecnologias. Considerando essa realidade, a utilização da robótica no contexto escolar tem esbarrado em profissionais da educação que ainda não se relacionam com a tecnologia por medo, resistência, preconceito de usar tais recursos ou por formação tecnológica insuficiente. Essa mudança requer uma sensibilização dos profissionais da educação, quanto à importância das tecnologias digitais, bem como a possibilidade de utilização de recursos de baixo custo que viabilizem a prática da robótica nas escolas.

O Arduino é uma plataforma aberta que permite o desenvolvimento da robótica com baixo custo, e de acordo com Geddes (2017 pág. 15), ele "pode ser programado 
para conectar e controlar vários componentes eletrônicos” a partir da utilização de uma placa simples com entradas e saídas, um ambiente desenvolvido de fácil assimilação e linguagem de programação C++. Geddes (2017 pág. 14) afirma ainda que “o Arduino pode ser usado para criar uma enorme quantidade de projetos", e essa criatividade pode ser aplicada na robótica utilizando componentes simples, material reciclado ou sucatas de forma interativa.

Na prática mais comum, a robótica educacional se dá em aulas presenciais com a utilização de kits, compostos por dispositivos eletrônicos. Atualmente, devido ao cenário da pandemia de Covid-19, onde a quarentena se tornou obrigatória em quase todo o mundo, inclusive no Brasil, a procura por cursos online cresceu, tornando-se uma forma de promover o desenvolvimento pessoal durante o isolamento, além de impelir a adequação à nova realidade educacional com o uso das tecnologias.

Considerando esse cenário de pandemia e a necessidade de formação para professores, a principal contribuição deste trabalho é favorecer uma aprendizagem de Robótica Educacional através de uma estratégia de baixo custo, online, com prática simulada e sem riscos. Dessa forma, a abordagem deste trabalho destaca o uso de um simulador online, como alternativa de baixo custo, sem o uso de kits físicos, para a prática de projetos educacionais de robótica.

Portanto, a relevância deste trabalho é tornar o acesso à robótica mais abrangente, com o objetivo principal de disponibilizar videoaulas em uma plataforma gratuita e aberta, como material didático, para a promoção de conhecimentos básicos de Robótica Educacional com o uso do simulador online Tinkercad, a ser aplicado no desenvolvimento de uma formação virtual para professores, estudantes e qualquer pessoa interessada nessa temática.

\section{Referencial teórico}

Há uma popularização dos aparelhos tecnológicos, principalmente entre os mais jovens. Eles estão inseridos no dia a dia de qualquer pessoa e a escola contemporânea não tem mais como se alienar diante dessa realidade. O papel do professor é fundamental para o uso da tecnologia no espaço escolar, e ele deve ter capacitação para orientar o uso adequado das tecnologias, mídias e softwares.

Entre as tecnologias para a educação, está a robótica educacional que, de acordo com Silva (2009), envolve um conjunto de processos e procedimentos para propostas de ensino e aprendizagem que tornam os dispositivos robóticos mediadores do 
conhecimento. Os PCN - Parâmetros Curriculares Nacionais (1998, pág. 34) evidenciam que o ensino com tecnologias resulta numa aprendizagem significativa e deve permitir que o aluno "compreenda detalhadamente o conteúdo abordado [...] explorando as potencialidades que estes lhe oferecem". A robótica no contexto educacional contempla essa aprendizagem significativa e oferece oportunidades para o desenvolvimento cognitivo do estudante por se tratar de um ferramenta pedagógica interdisciplinar, quando propõe, segundo Dias, Abdalla e Saba (2015), em trabalhos práticos a mistura de conceitos abordados por diferentes disciplinas.

\section{Formação de professores para a robótica educacional}

Fazendo uma relação entre as gerações e o uso das tecnologias, vamos discutir as habilidades tecnológicas dos professores da atualidade, sendo eles em sua maioria pertencentes à geração $\mathrm{X}$, considerados como imigrantes digitais. Mark Prensky, estudioso e criador dos termos nativos digitais e imigrantes digitais, foi entrevistado por Gomes (2018) e definiu os imigrantes digitais como aqueles que "chegaram à tecnologia digital mais tarde na vida e, por isso, precisaram se adaptar" a elas. Prensky ainda pontua que não houve mudanças no processo de aprendizagem, mas sim que o "que está mudando são as ferramentas que ajudam na aprendizagem".

Considerando a realidade e a necessidade de formação dos professores para o uso de tecnologias digitais na educação mediante o perfil de alunos do século XXI, de acordo com Richit (2014), é importante que tanto alunos como professores se apropriem das "tecnologias de maneira ativa, crítica, reflexiva e inclusiva". A autora destaca ainda que a inclusão digital deve fundamentar as ações de formação dos professores fomentando práticas voltadas ao desenvolvimento da educação em sua totalidade.

Para Libâneo (2004), a formação permite que o professor desenvolva competência profissional e envolve o uso de conhecimentos e capacidades para fazer um trabalho reflexivo por meio desses novos saberes. Portanto, para que os professores da Educação Básica possam adotar a prática da robótica em um contexto pedagógico, é importante ressaltar que ele pode e deve estar preparado para absorver esse novo contexto educacional que lhe é apresentado. Para isso, ele deve alinhar-se com novos aprendizados para enfrentar os desafios da educação na "atual' realidade tecnológica.

Para atender às necessidades pontuadas, e mediante o período de isolamento social em que a aprendizagem virtual se faz tão presente, visamos contribuir na formação de professores com a produção de videoaulas que lhes permitirão um co- 
nhecimento introdutório da robótica educacional, numa proposta de aprendizagem virtual com a utilização do simulador Tinkercad.

\section{uso de simuladores no contexto educacional}

O uso de simuladores no espaço escolar tem por objetivo facilitar o processo de ensino e de aprendizagem, logo, essa metodologia permeia a visualização e a interação com o objeto de aprendizagem. Segundo Baladez (2016), o simulador computacional utiliza-se do jogo para ensinar e desenvolver conhecimento, tornando-o palpável e evidente diante de nossos olhos. Nesse sentido, os simuladores não pretendem substituir os outros materiais didáticos, como os livros, eles completam a aprendizagem permitindo a visualização na prática dos conteúdos ensinados anteriormente. Além disso, minimizam os riscos de acidentes e perdas de equipamentos.

A Robótica Educacional, em geral, é desenvolvida com a utilização de kits e, segundo Fernandes (2013), os kits de robótica no Brasil são importados e de alto custo, tornando restrito a inserção da robótica na educação. Essa realidade faz com que o uso de simuladores virtuais, nos programas com Robótica Educacional, sejam uma opção viável por não requerer o uso de kits físicos, sendo necessário somente ter acesso a um computador ou dispositivos móveis e internet.

Em tempos de pandemia, o uso de simuladores virtuais apresentam vantagens ao permitir ao estudante uma capacitação bem realista, em um espaço de sua própria escolha, não exigindo a sua locomoção para outro ambiente de aprendizagem, respeitando assim, as recomendações da $\mathrm{OMS}^{1}$ - Organização Mundial de Saúde que sugere, no momento atual, distanciamento social.

\section{○ Tinkercad para a prática da Robótica Educacional}

O Tinkercad é uma plataforma virtual, aberta e gratuita que permite a prática de simulação, montagem e a programação de protótipos utilizando circuitos eletrônicos digitais. $\mathrm{O}$ ambiente de desenvolvimento é simples e possibilita que pessoas que não têm conhecimentos de engenharia, não possuem kits do Arduino e que estão impossibilitadas de trabalhar presencialmente possam praticar a robótica.

Segundo Medeiros e Wünsch (2019), o simulador Tinkercad reproduz da forma mais fiel possível, o desempenho dos circuitos, constituindo-se numa ferramenta bastante útil para o aprendizado inicial de programação em Arduino, além de dar 
autonomia e motivação ao aluno no seu processo de aprendizagem, permitindo novas descobertas e possibilidades de uso.

Portanto, considerando a atual necessidade de qualificação dos professores, estaremos expondo como a utilização do simulador Tinkercad contribuiu para o desenvolvimento de um curso de Robótica Educacional em ambiente totalmente online. Oportunizando com essa experiência debates e discussões no que se refere a novas propostas pedagógicas que poderão ser inseridas no contexto educacional após retorno das atividades presenciais. Na próxima seção estaremos apresentando, de forma breve, como desenvolvemos um curso em ambiente virtual.

\section{A Proposta de uso do Tinkercad em um curso online de Robótica}

Essa pesquisa foi desenvolvida com enfoque descritivo e caráter qualitativo. Para iniciar a pesquisa foi realizada uma revisão de literatura, com a intenção de fundamentar teoricamente ações que tiveram como objetivo desenvolver uma formação para professores, de forma virtual, de Robótica Educacional com o uso de um simulador online. O curso "Oficina online de introdução à Robótica Educacional” ofertou (40) quarenta vagas, com carga horária de 20 horas, tendo ao final do período de inscrição 564 candidatos.

O ambiente de simulação e a introdução de uso do Tinkercad se deu em dois momentos. O primeiro assíncrono, a partir de uma videoaula ${ }^{2}$, na qual os cursistas foram convidados a conhecer a utilização dos circuitos do Arduíno e os conceitos básicos de programação na prototipagem virtual. A oficina contemplou ainda, um momento síncrono, em WebConferência, onde foram apresentados aos cursistas, a prática de simulação no Tinkercad.

A análise qualitativa dos dados, ocorreu por meio de formulários e Fóruns que permitiram aos cursistas realizarem uma avaliação da oficina e do material didático, quanto a sua potencialidade para contribuir com a aprendizagem de robótica de forma virtual. As informações coletadas serão descritas na seção seguinte.

\section{Relato de experiência}

Para conduzir essa abordagem e com o objetivo de promover uma reflexão e reorientação para estratégias de inovação nas práticas educativas, o curso contou com 
um ambiente virtual de aprendizagem, sendo ministrado por alunos do programa de Mestrado Profissional, Educação em Ciências e Matemática do IFES (EDUCIMAT), como uma ação de extensão da disciplina de "Tecnologias Educacionais IV".

O curso "Oficina online de introdução à Robótica Educacional" teve a duração de quinze dias, foi realizado em modelo de ensino remoto, através das atividades síncronas e assíncronas nas plataformas Moodle com o objetivo de desenvolver a teoria e a prática que envolve projetos com conhecimentos de pensamento computacional, programação e robótica.

A divulgação e as inscrições ocorreram por meio de publicação no site da instituição, entre os dias 12 a 26 de junho de 2020 , e dos 564 candidatos foram selecionados os 40 primeiros inscritos. O público alvo foram professores de Educação Básica, Técnico e Superior. As atividades foram desenvolvidas em parceria e colaboração com IFES/CEFOR, a partir das plataformas Moodle, Tinkercad e Rnp de Webconferência, conforme apresentado nas Figura 1 e 2.

Figura 1: Área do curso no ambiente Robótica educacional para professores

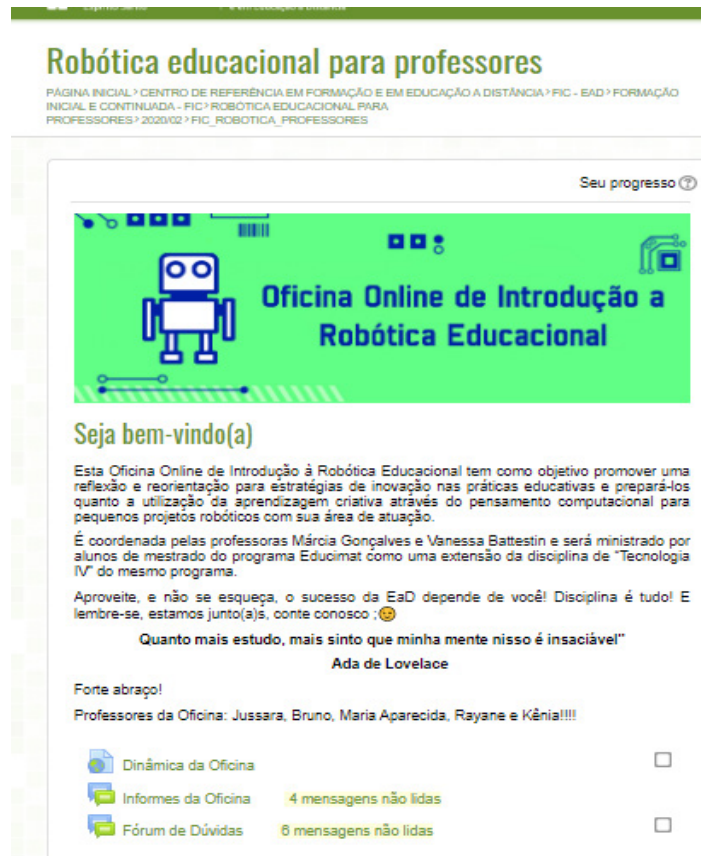

Fonte: Acervo pessoal 2020.
Figura 2: Área virtual no ambiente do curso Robótica educacional

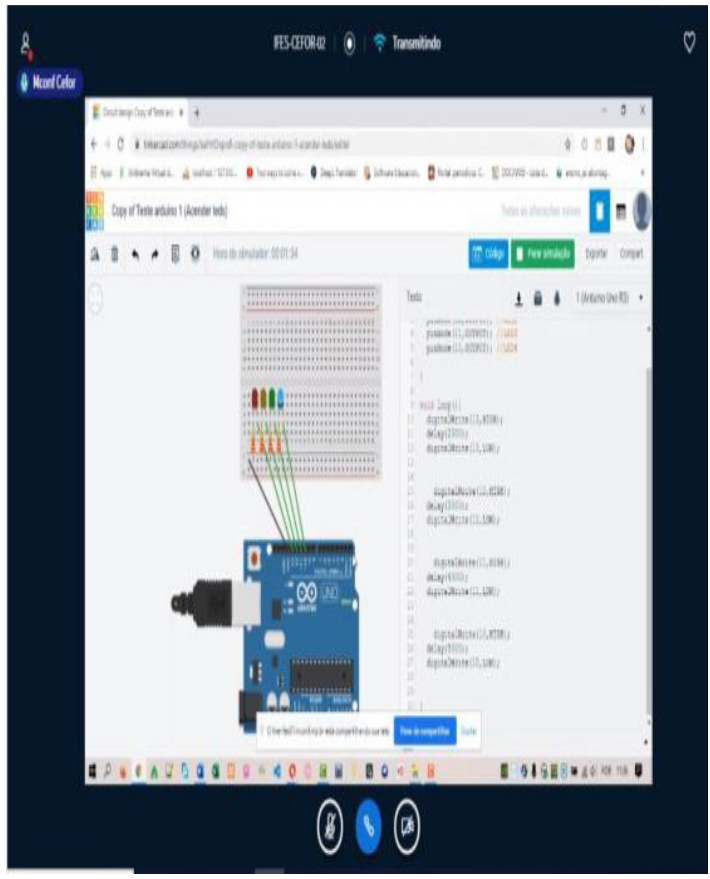

Fonte: Acervo pessoal 2020. 
A webconferência contou com a participação dos cursistas e dos tutores, em uma oficina online de introdução a Robótica Educacional com duração de três horas. Os tutores apresentaram o ambiente Tinkercad, instruindo quanto à realização de cadastro e a criação de projetos. Entres as vantagens de utilização do Tinkercad para o contexto de ensino online (e híbrido, considerando o período pós-pandemia), destacaram-se a gratuidade da ferramenta, seu design colaborativo e a possibilidade de prática de programação embarcada.

A discussão seguinte considerou um diálogo sobre conceito de programação, tipos de linguagem e suas principais características, comandos básicos de estruturação e pôr fim a programação em blocos, específica do Tinkercad. A partir desse roteiro, discorreram conceitos sobre o Arduino, e seus principais componentes, em destaque, led, placa LCD, cabo USB, jumpers, os resistores, capacitores, indutores, chaves, botões, potenciômetros, circuitos integrados, protoboard, multímetros, gerador de funções e osciloscópio.

Na sequência, foi iniciado um projeto de circuitos, onde os cursistas conheceram as ações básicas para realizar a atividade proposta Acendendo um LED. Através das atividades desse projeto, os alunos tiveram a oportunidade de inserir componentes e disparadores, realizar a montagem virtual da placa protoboard, exportar e compartilhar o projeto desenvolvido. A Figura 3 apresenta esse projeto no simulador Tinkercad e a Figura 4, a sua programação em blocos.

Figura 3: Ambiente virtual Tinkercad

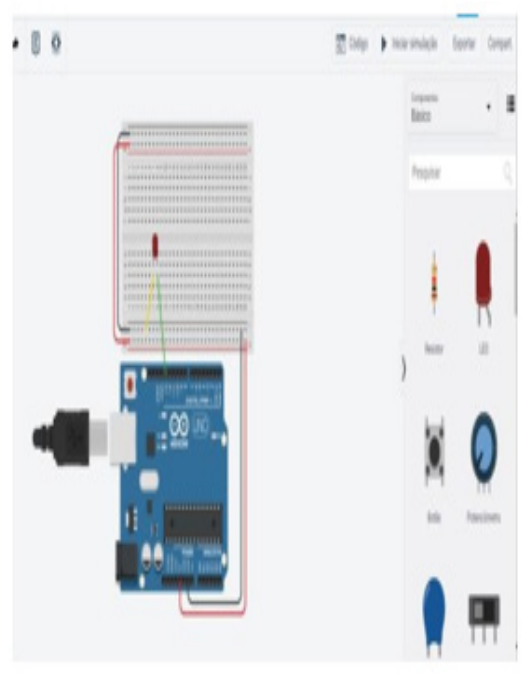

Fonte: Site Tinkercad, 2020 - www.tinkercad.com.br
Figura 4: Ambiente virtual Tinkercad

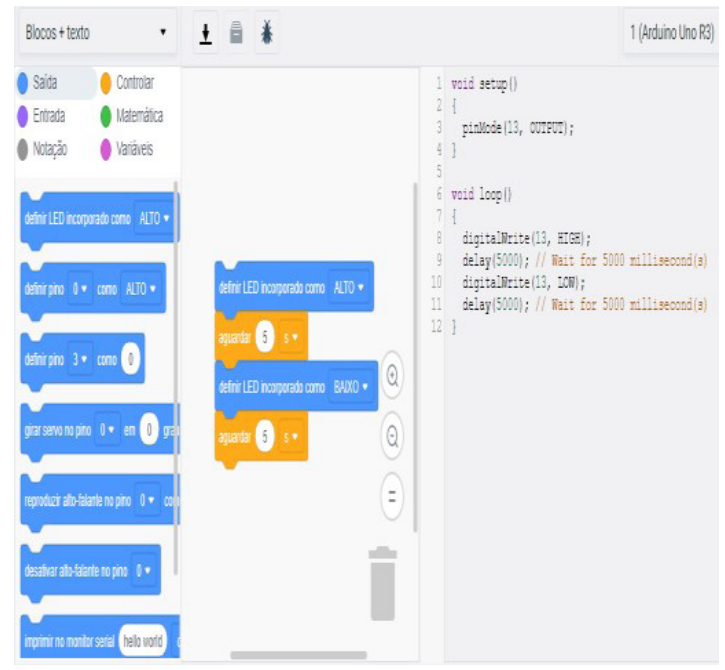

Fonte: Site Tinkercad, 2020 - www.tinkercad.com.br 
Contemplamos, ao final da aula, discussões sobre o ícone "Código" que compreende a programação do circuito e função em blocos. Destacaram-se componentes básicos de linguagem de programação como saída, entrada, notação, controle, matemática e variáveis, com uma abordagem introdutória aos itens citados.

\section{Resultados e análise de dados}

No que se refere a coleta de dados, elaboramos previamente um roteiro de perguntas objetivas e discursivas. A primeira análise foi realizada a partir dos dados coletados no ato das inscrições. Foram sugeridas nove questões objetivas que permitiram traçar o perfil dos 40 cursistas, tais como sexo, formação inicial e área de atuação profissional, experiências anteriores na realização de cursos EaD e por fim se já teriam conhecimentos prévios em robótica.

Na segunda análise, foram sugeridas duas questões discursivas com a finalidade de analisarmos quais mudanças ocorreram ou poderiam ocorrer na prática pedagógica após a conclusão desse curso, e, por último, perguntamos se o participante do curso indicaria o uso do simulador Tinkercad para o ensino e aprendizagem de introdução à robótica por meio virtual.

Tendo em vista a análise desses dados coletados, é possível considerarmos algumas conclusões. No que tange ao objetivo de ofertar uma formação na plataforma Moodle para o ensino de robótica educacional, visando o público de professores, foi alcançado e se reflete na participação de $70 \%$ dos inscritos serem professores. Ainda sobre essa vertente, o curso teve em sua totalidade 564 inscrições, o que ilustra uma procura significativa por parte desse público que busca, mesmo em meio a pandemia e em contexto de isolamento social, uma disposição à qualificação profissional. A partir dessa perspectiva, reflete-se e analisa-se o papel dos professores que assumem a importância da tecnologia na atualidade e o seu papel como instrumento educativo.

Ainda, tomando como base os dados coletados, $80 \%$ dos inscritos afirmam não ter conhecimento em robótica conforme o Gráfico 1 . Além disso, $50 \%$ deles, mencionaram ter curiosidade a respeito, sendo este o principal fator de interesse pela oficina, como evidencia o Gráfico 2. Essa afirmação nos permite supor que há necessidade de fomentação de cursos de capacitação para professores em robótica educacional. 


\section{Gráfico 1: Você já fez algum curso de Robótica Educacional?}

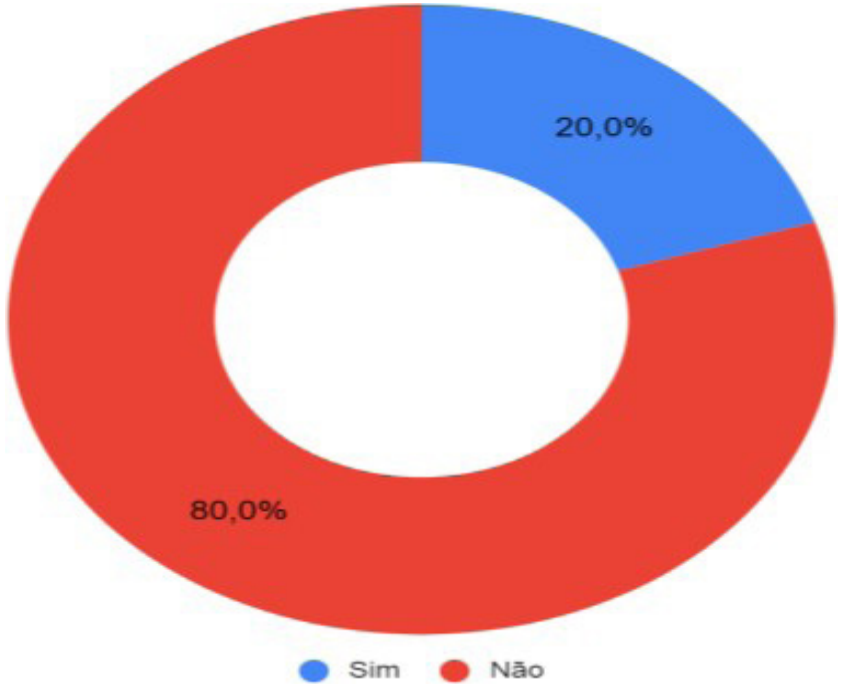

Fonte: Autoria própria, 2020

\section{Gráfico 2: Porque você se inscreveu no curso?}

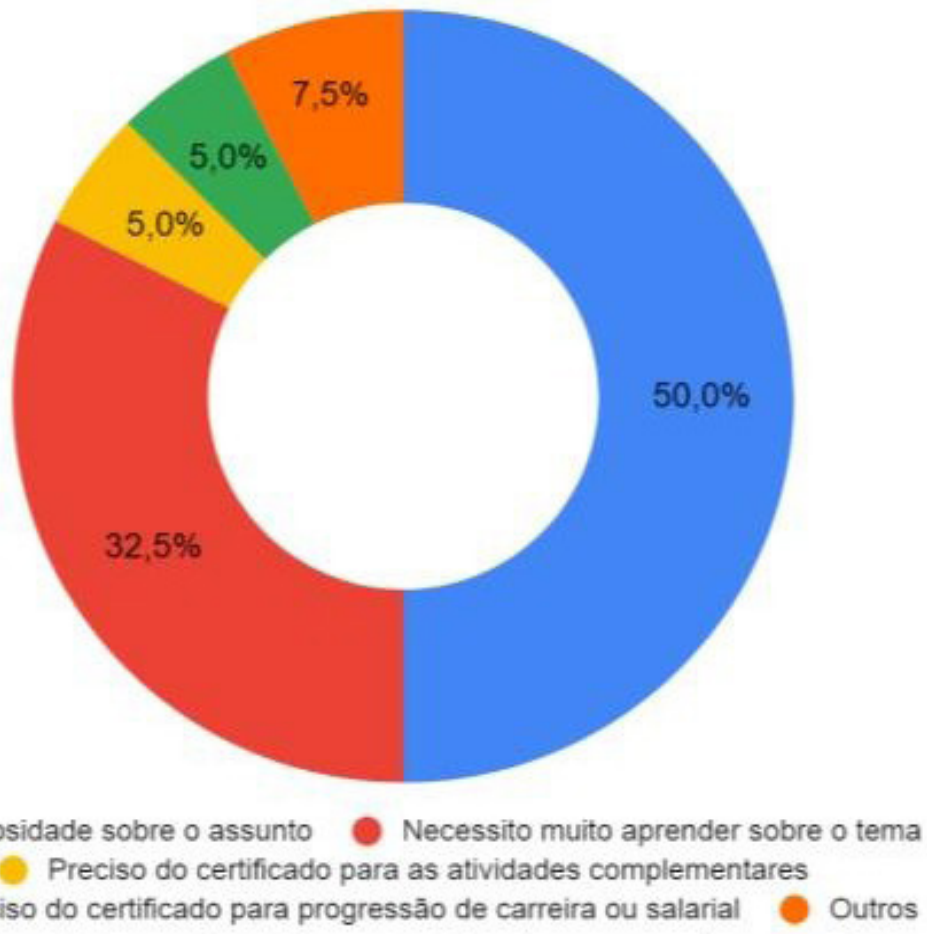

Fonte: Autoria própria, 2020. 
No ambiente Moodle de execução da oficina, destacam-se, nas Atividades de Fóruns, um espaço interativo de discussões e relatos das perspectivas acerca da videoaula que lhes permitiu um conhecimento introdutório da robótica educacional, em uma proposta de aprendizagem virtual com a utilização do simulador Tinkercad. Nesse ambiente coletivo, destacamos, na Tabela 1, o relato de três cursistas que apresentaram a relevância da videoaula disponibilizada na oficina como material didático.

Tabela 1: Depoimento dos cursistas no Fórum

\begin{tabular}{c|l}
\hline Cursista & \multicolumn{1}{c}{ Depoimento } \\
\hline Cursista X & $\begin{array}{l}\text { "Eu nunca trabalhei com nada parecido e não tinha noção alguma de programação. Amei a } \\
\text { facilidade de mexer no programa, mas sem o tutorial provavelmente não teria conseguido. } \\
\text { Consegui fazer o projeto com facilidade seguindo o passo a passo do vídeo. Logo em se- } \\
\text { guida comecei a fazer várias tentativas mudando a localização, resistência, colocando mais } \\
\text { leds, para tentar entender melhor o funcionamento". }\end{array}$ \\
\hline Cursista Y & $\begin{array}{l}\text { "Tive um pouquinho de dificuldade indo pela intuição e tive que rever o vídeo da professora } \\
\text { com as explicações. Depois ficou fácil, coloquei dois leds piscando. O programa é top!” }\end{array}$ \\
\hline Cursista Z & $\begin{array}{l}\text { "Confesso que preciso estudar mais e explorar novas possibilidades de uso do Arduíno em } \\
\text { projetos robóticos. Com a tutoria virtual promovida pela vídeo aula postada, foi possível a } \\
\text { montagem do mesmo projeto demonstrado. Não achei difícil, porém, sem o aporte teórico- } \\
\text {-metodológico, seria impossível a consecução da programação proposta". }\end{array}$
\end{tabular}

Fonte: Dados extraídos do Ambiente virtual da Oficina Online Robótica educacional

Nesse coletivo de depoimentos, entendemos que a videoaula favoreceu o processo de aprendizagem e igualmente a motivação para novas formações.

As questões discursivas do questionário de avaliação tiveram a finalidade de analisar a aplicabilidade do simulador Tinkercad para aprendizagem introdutória da robótica, sendo realizadas as seguintes perguntas:

I - Você indicaria o uso do simulador Tinkercad para o ensino e aprendizagem de introdução a robótica por meio virtual? As resposta obtidas mostraram que $100 \%$ indicariam o simulador;

II - Quais mudanças ocorreram ou podem ocorrer nas suas práticas pedagógicas após a conclusão desse curso? Os resultados obtidos mostraram que 82,35\% dos participantes acreditam que suas aulas se tornarão mais dinâmicas com os conhecimentos adquiridos, que a oficina proporcionou discussões que ampliam as possibilidades de inserir a robótica em suas práticas pedagógicas e por fim, indicam o interesse de aprofundar seus estudos sobre simuladores virtuais e estudo de programação. 


\section{Conclusões e Perspectivas futuras}

Finalizando este trabalho consideramos que a Robótica Educacional tem sido apontada como uma ferramenta pedagógica que desperta o interesse e a criatividade do estudante, de forma lúdica. No entanto, para que essa ferramenta possa ser assumida no ambiente educacional, é necessário que os profissionais envolvidos tenham uma capacitação que ofereça conhecimentos de robótica, envolvendo a programação e a montagem de protótipos.

A formação foi conduzida no modelo $\mathrm{EAD}$, sendo essa modalidade virtual uma proposta viável, de baixo custo e que atende à demanda mundial por formação com e para o uso de tecnologias educacionais. A avaliação do curso e a função pedagógica do material didático foi obtida na coleta de dados, evidenciando como foi o processo de aprendizagem para os cursistas e usuários dessa proposta de formação para professores.

Diante das informações coletadas e considerando as afirmações nos Fóruns de debate, fica evidente que os sujeitos da pesquisa em sua maioria tiveram poucas limitações para a realização das atividades solicitadas no decorrer da oficina. De acordo com estes mesmos dados, torna-se claro a contribuição do material didático, incluindo as videoaulas e tutoriais utilizados nesse processo.

Como o curso teve o interesse e a adesão de professores de diversas regiões do país, para os elaboradores dessa proposta, ficou o interesse em dar continuidade a formação de professores, agora numa proposta que permita a realização de um curso aberto em ambiente virtual de aprendizagem - MOOC com o uso do simulador Tinkercad, visando atender um número maior de participantes, oportunizando a aprendizagem a distância de introdução à Robótica Educacional.

\section{Online Teacher Training in Educational Robotics with Practices in the Tinkercad Simulator}

\section{Abstract}

In recent decades, technological transformations have brought about changes in social, political, economic relations and, consequently, in the role of the contemporary school. This scenario accelerated the challenge on the part of teachers and other education professionals in the search for greater qualification, demanding competences and skills that have become fundamental in 
today's society. In this sense, this work presents the use of the Tinkercad simulator in a virtual course of introduction to robotics promoted by students of the Professional Master's program, Education in Science and Mathematics - EDUCIMAT - IFES / CEFOR, as an extension of the "Educational Technologies IV" discipline. Tinkercad is an online platform that allows the simulation of digital electronic circuits, including the use of Arduino. The importance of this work is evident in the fact that the modality of teaching and learning in a virtual environment has become a reality in recent decades, especially in the context of the Covid-19 pandemic.

Keywords: Educational Robotics, Teacher training, Arduino, Tinkercad.

\section{Notas}

1 OMS - A Organização Mundial da Saúde ou (World Health Organization), é uma agência especializada das Nações Unidas, destinada às questões relativas à saúde. A OMS tem um entendimento de Saúde como um estado completo de bem-estar psicológico, físico, mental e social. A OMS publicou um Plano Estratégico de Preparação e Resposta à COVID-19, que identifica as principais ações que os países precisam tomar e os recursos necessário para realizá-las.

2 Link da videoaula - https://www.youtube.com/watch?v=Ic7gISMe1DY

\section{Referências}

BALADEZ, Fábio. O passado, o presente e o futuro dos simuladores. FaSCi-Tech, v. 1, n. 1, 2016.

BRASIL, Ministério da Educação e do Desporto. Secretaria da Educação Básica. Parâmetros Curriculares para o Ensino Fundamental; Matemática. Brasília, MEC/SEB, 1998.

DE MEDEIROS, Luciano Frontino; WÜNSCH, Luana Priscila. Ensino de programação em robótica com Arduino para alunos do ensino fundamental: relato de experiência. Revista Espaço Pedagógico, v. 26, n. 2, p. 456-480, 2019.

DIAS, Josualdo; ABDALLA, Débora; SABA, Hugo. Ensino da robótica livre como instrumento de aprendizado interdisciplinar na rede pública de educação profissional e tecnológica. In: Anais do XXIII Workshop sobre Educação em Computação. SBC, 2015. p. 236-245.

FERNANDES, Carla da Costa. S-educ: Um simulador de ambiente de robótica educacional em plataforma virtual. 2013. Dissertação de Mestrado. Universidade Federal do Rio Grande do Norte.

GEDDES, Mark. Manual de Projetos do Arduino: 25 projetos práticos para começar.São Paulo. Novatec Editora, 2017.

GOMES, Patrícia. Leia entrevista do autor da expressão imigrantes digitais'. Folha de S. Paulo, 2018.

LIBÂNEO, J. C. Organização e Gestão da Escola. Teoria e Prática. Goiânia: Alternativa, 2004.

MANFREDINI, Benedito Fulvio. Tecnologia na escola: abordagem pedagógica e abordagem técnica. 2014. São Paulo. Cengage Learning.

RICHIT, Adriana. Formação de Professores em Tecnologias Digitais: desdobramentos nas práticas escolares em face do Programa Um Computador por Aluno. Uni- pluriversidad, v. 14, n. 3, p. 81-93, 2014. 
SILVA, Alzira Ferreira da. RoboEduc: Uma metodologia de aprendizado com Robótica Educacional. 2009.

ZILLI, Silvana do Rocio et al. A robótica educacional no ensino fundamental: perspectivas e prática. 2004. 